\title{
Lactate Dehydrogenase Isoenzyme 2 Measurement
}

National Cancer Institute

\section{Source}

National Cancer Institute. Lactate Dehydrogenase Isoenzyme 2 Measurement. NCI

Thesaurus. Code C74888.

The determination of the lactate dehydrogenase isoenzyme 2 present in a sample. 